\title{
What's next after the clot? Residual Pulmonary Vascular Obstruction after pulmonary embolism: from imaging finding to clinical consequences.
}

PB Bonnefoy 1 , V Margelidon-Cozzolino, ${ }^{2,3}$, J Catella-Chatron², E Ayoub ${ }^{2}, \mathrm{JB}_{\text {Guichard }}^{4,5}$, M Murgier $^{3,6}$, L Bertoletti ${ }^{2,6,7,8}$

\section{Institutions}

1. Service de médecine nucléaire, CHU de St-Etienne, Saint-Etienne, France.

2. Service de Médecine Vasculaire et Thérapeutique, CHU de St-Etienne, Saint-Etienne, France.

3. Intensive Care Medicine Department (Réanimation G), Hôpital Nord, CHU de Saint-Etienne.

4. Department of Cardiology, University Hospital of Saint-Étienne, Université Jean Monnet, Saint-Étienne, France

5. Department of Medicine and Research Center Montreal Heart Institute and Université de Montréal, Montreal, Quebec, Canada

6. INSERM, UMR1059, Equipe Dysfonction Vasculaire et Hémostase, Université Jean-Monnet, F-42055, Saint-Etienne, France ;

7. INSERM, CIC-1408, CHU Saint-Etienne, F-42055, Saint-Etienne, France.

8. F-CRIN INNOVTE network, Saint-Etienne, France.

\section{Corresponding author:}

Pierre-Benoît BONNEFOY, MD

Service de Médecine Nucléaire, CHU de Saint-Etienne, 42055, Saint-Étienne, France. pierre.benoit.bonnefoy@gmail.com

Tel: 00334778283 18 / Fax: 0033477828473

ORCID 0000-0002-6334-7066

\section{Email Address :}

pierre.benoit.bonnefoy@gmail.com

vmargelidon@gmail.com

jcatella@gmail.com

ay.elie30@gmail.com

jeanbaptiste.guichard@hotmail.com

m.murgier@hotmail.fr

laurent.bertoletti@gmail.com 


\begin{abstract}
(250 words)
Surviving an embolism exposes patients to potential long-term complications, such as altered quality of life, persistent dyspnea, impaired exercise capacity or pulmonary hypertension. The common objective factor in most of these situations is the presence of residual pulmonary vascular obstruction (RPVO). Planar ventilation/perfusion scintigraphy (V/Q lung scan) is the gold standard for assessing RPVO, which occurs in 46 to $66 \%$ of patients at 3 months and persists in 25 to $29 \%$ of patients a year after acute PE. Assessed early (i.e. before discharge), RPVO could predict acute PE development with a high negative predictive value. Evaluated after anticoagulation therapy, RPVO could help to manage anticoagulation treatment and predict the risk of PE recurrence and patients identified at risk of developing chronic thromboembolic pulmonary hypertension.

In this comprehensive review, we provide an overview of the current knowledge of RPVO after PE from imaging diagnosis to clinical consequences. In the first part, we mainly focus on the imaging modalities capable of detecting and quantifyng RPVO. We then focus on the symptoms and syndromes linked with this residual obstruction after PE. Although the occurrence of RPVO and long-term complications varies greatly from one patient to another, we finally aim to identify the patients and diseases at risk of developing residual obstruction.
\end{abstract}

Keywords (maximum of 6),

residual pulmonary vascular obstruction, V/Q scan, CTPA, pulmonary embolism, chronic thromboembolic pulmonary hypertension. 


\section{Introduction}

Major progress achieved in diagnostic and therapeutic strategies has substantially improved the short-term prognosis of patients with pulmonary embolism (PE). This has allowed to reduce overall short-term mortality of PE patients, which is now very low [1]: 30-day overall mortality have decreased from 6.6 to $4.9 \%$, whereas mortality directly-linked to PE dropped to less than $2 \%$ at 3-months [2]. The rise of direct oral anticoagulants (DOACs) has simplified the management of anticoagulant treatment [3]. These improvements in PE management have led to a shift in our conception of venous thromboembolism (VTE) from an acute to a chronic condition. Indeed, surviving an embolism exposes patients to potential long-term complications, justifying the recent development of the "post-PE syndrome [4]" concept. This syndrome includes all the health status deteriorations of patients due to the sequelae attributed to PE [5]. Up to $50 \%$ of patients may suffer from this syndrome which is defined as altered quality of life, persistent dyspnea and/or impaired exercise capacity. The common objective factor in most of these situations is the presence of residual pulmonary vascular obstruction (RPVO) assessed by pulmonary perfusion scintigraphy. Planar ventilation/perfusion scintigraphy (V/Q lung scan) is the gold standard [6,7] for this evaluation. It is the only tool with a sufficient negative predictive value to exclude unfavorable progression. RPVO is associated with a significant clinical impact (decreased quality of life, functional impairments such as dyspnea and/or decreased exercise capacities) [8], and the cornerstone of the most threatening PE long-term complication: chronic thromboembolic hypertension (CTEPH). The factors predicting RPVO emergence (as predictive factors of CTEPH) are still unclear. RPVO appears to be a necessary, but not sufficient, condition to explain the clinical impairment and progression to CTEPH. Although RPVO is a frequent consequence of PE, it is not currently recommended to perform a systematic V/Q lung scan in all patients to screen for this adverse progression $[9,10]$. In the 
presence of CTEPH symptoms, only 55\% of patients are examined using recommended imaging techniques $[10,11]$ meaning only $20 \%$ of symptomatic patients were examined using computed tomography pulmonary angiography (CTPA) and $<6 \%$ with the gold standard (i.e. V/Q scan), reflecting poor knowledge of the impact of RPVO on clinical impairment and a possible improvement in clinical management.

In this comprehensive review, we provide an overview of the current knowledge on RPVO after PE from imaging diagnosis to clinical consequences. In the first part, we mainly focus on the imaging modalities capable of detecting and quantifying RPVO. We then focus on the symptoms and syndromes linked with this residual obstruction after PE. Although the occurrence of RPVO and long-term complications varies greatly from one patient to another, we finally aim to identify the patients and diseases at risk of developing residual obstruction. 


\section{Methods}

\section{Design, information sources and search strategy}

We searched PubMed and Google Scholar to identify relevant eligible original article, systematic reviews and meta-analyses to conduct a comprehensive review about RPVO after PE.

The Medical Subject Heading (MeSH) terms and free keywords were used to identify article. We combined search terms for applied technique (CTPA, V/Q scan, or SPECT/CT V/Q) and disease (Residual vascular pulmonary obstruction, RPVO, embolic sequels, chronic thromboembolic pulmonary hypertension, CTEPH).

\section{Inclusion and exclusion criteria}

Studies were included based on the following criteria: original article, systematic reviews and meta-analyses about residual vascular obstruction after acute pulmonary embolism.

The exclusion criteria were as follows: an abstract, case report, or letter; animal study; and duplicate report. If the data were duplicated or the same population was used in $>1$ study, the most recent or complete study were chosen. The published language was limited to English or French.

\section{Study selection}

After a first selection based on titles and abstracts of search results, a final selection was made after a full article reading. Articles with detailed methodology about RPVO evaluation were preferred. Apart from historical considerations or highly quality paper, the most recent articles were preferred. 


\section{I - Residual Pulmonary Vascular Obstruction}

RPVO can be defined as incomplete repermeabilization of the pulmonary arteries after acute PE. The persistent vascular occlusion causes alteration of the distribution of pulmonary perfusion which can be assessed by several imaging techniques.

\section{I-1 RPVO assessment with ventilation/perfusion lung scan}

V/Q lung scan is a scintigraphy technique based on direct assessment of both perfusion and ventilation. Pulmonary perfusion $(\mathrm{Q})$ is assessed by human macro-aggregated albumin labeled with $99 \mathrm{~m}$-Technetium (99m Tc-MAA). These macro-molecules are distributed in the capillary network according to the blood flow. Due to their size, slightly greater than the capillary diameter, they are trapped in capillaries reflecting the perfusion distribution. Pulmonary ventilation (V) can be assessed by various agents, gas ( ${ }^{81 \mathrm{~m} K r y p t o n)}$ or aerosols (aerosolized ${ }^{99 \mathrm{~m}} \mathrm{Tc}$ carbon particles - Technegas $\left.{ }^{\circledR}\right)$. These radiopharmaceutical tracers are distributed into the alveoli or bronchioles reflecting the ventilation distribution. A typical aspect of $\mathrm{PE}$ is V/Q mismatch: alteration of perfusion reflecting a vascular territory (triangular shape with peripheral base) associated with preserved ventilation. Post-embolic sequelae appear in the same pattern. Planar scintigraphy consists of an acquisition in 6 to 8 distinct projections (anterior, posterior, oblique). It is the historical technique in clinical strategies for acute PE diagnosis [12] validated by the PIOPED studies [13-15], which has demonstrated the high negative predictive value and defined the criteria of interpretation for acute PE. In acute PE diagnosis, use of the V/Q scan has decreased but remains relevant in specific populations [16]. However, V/Q scan is recommended in pulmonary hypertension to screen for CTEPH [6] because a normal V/Q scan effectively excludes CTEPH with sensitivity of $90-100 \%$ and specificity of $94-100 \%$ [17,18]. V/Q Single Photon Emission Computed Tomography (SPECT) is a more recent technique, mainly developed 
for acute PE [19]. It is based upon a volume acquisition from different angles. It can be combined with CT leading for enhanced specificity [20]. This technique appears promising compared to planar V/Q scan with increased sensitivity, specificity and better cost-efficiency [21,22]. However, appropriate specific validation is required, which is currently underway in PE diagnostic strategies through the SPECTACULAR trial (NCT02983760). Although SPECT is not yet recommended in the current guidelines, an increasing number of clinical trials are evaluating V/Q SPECT in RPVO exploration [23,24]. This technical innovation seems appropriate for RPVO assessment in order to tailor anticoagulation therapy or predict the risk of recurrence [25]. It has also been described to evaluate the response to balloon pulmonary angioplasty in CTEPH [26].

From a radiograpic point of view, RPVO is defined as a pulmonary vascular obstruction score greater than $10 \%$ on the planar V/Q lung scan, assessed after at least 3 months of appropriate anticoagulation therapy. For its assessment, Meyer et al. suggested a visual index evaluated in comparison to pulmonary angiography [27]. It can be briefly described as follows (Figure 1):

(1) each lobe is assigned a weight based upon the regional distribution of pulmonary blood flow in the supine position: right lower lobe $25 \%$, right middle lobe $12 \%$, right upper lobe $18 \%$, left lower lobe $20 \%$, lingula $12 \%$ and left upper lobe $13 \%$;

(2) for each lobe, a semi-quantitative perfusion score $(0,0.25,0.5,0.75$ or 1$)$ is estimated from the film density in the anterior, posterior and oblique views by comparison with the photodensity of an apparently normally perfused area;

(3) each lobar perfusion score is then calculated by multiplying the weight by the perfusion score; and 
(4) the overall perfusion score is determined by summing the six separate lobar perfusion scores and the percentage of vascular obstruction is then calculated as (1- overall perfusion score) x 100.

The first study to assess RPVO with a lung scan was the Urokinase Pulmonary Embolism Trial (UPET) [28,29]. The results of this study, published in 1970, are still considered as a standard. Patients were closely followed with a lung scan from the first 14 days following PE diagnosis up to 1 year. They reported a progressive decrease in RPVO over time. At 1-year follow-up, a normal pattern was found in only $75.8 \%$ of patients. There were no significant changes in RPVO reported after 3 months of anticoagulant therapy.

In 2006, Nijkeuter et al [30] published a systematic review on residual obstruction after acute PE. They found that $57 \%$ of patients had incomplete resolution of PE six months after diagnosis. Their work highlighted the significant variability between studies in terms of population characteristics, duration of $\mathrm{PE}$ treatment course, assessment techniques and duration of follow-up.

A recent study, performed in 2017 on 83 prospective patients, used SPECT lung scan to assess RPVO after acute PE [23]. RPVO was assessed after 6 months of anticoagulation therapy with semi-quantified SPECT using perfusion sequences (Q-SPECT). After a 6-month follow-up, they reported a RPVO rate similar to that of planar lung scan of approximately $52 \%$.

\section{I-2 Other techniques for RPVO evaluation}

Radiological tools have been used in addition to scintigraphy techniques in the field of acute and chronic venous thromboembolic disease. These techniques, validated in the early $2000 \mathrm{~s}$ [31,32], have become the first-line test in acute PE diagnosis strategies [33]. 
CTPA uses iodinated contrast agents to opacify the pulmonary arteries to at least the segmental level. It aims to directly visualize the clot in the acute PE. In chronic PE, CTPA aims to visualize residual clots with specific patterns such as mural filling defects, webs, irregular thickening of the vessel wall with reduced caliber or calcified residual thrombus [34]. Multidetector computed tomography (MDCT) has progressively replaced single-detector computed tomography (SDCT) leading to an improvement in quality associated with a moderate improvement in irradiation [35-37]. Some recent advances have been achieved in RPVO assessment using CT techniques. Like Meyer with the planar lung scan, Qanadli et al. defined a specific index to quantify pulmonary arterial obstruction and compare it prospectively with the angiographic index [38]. The CT Qanadli obstruction index became a standard in many studies to evaluate initial PE severity [8,39] and/or during follow-up [40,41]. It can be determined as follows (Figure 2):

(A) The arterial tree of each lung is divided into 10 segmental arteries (three to the upper lobes, two to the middle lobe and to the lingula, and five to the lower lobes).

(B) 1 point is attributed to the presence of an embolus in a segmental artery. Some emboli in the most proximal arterial level are scored a value equal to the number of segmental arteries arising distally.

(C) To provide additional information on the residual perfusion distal to the embolus, a weighting factor is assigned to each value, depending on the degree of vascular obstruction. This factor is equal to zero when no thrombus is observed; 1 , when a partially occlusive thrombus is observed; or 2 with total occlusion.

(D) The percentage of vascular obstruction is calculated by dividing the patient score by the maximal total score (40 par patient) and by multiplying the result by 100 . Therefore, the CT obstruction index can be expressed as: $\Sigma(\mathrm{n} \mathrm{x} \mathrm{d}) / 40 \times 100$, where 
$\mathrm{n}$ is the value of the proximal thrombus in the pulmonary arterial tree equal to the number of segmental branches arising distally (minimum, 1; maximum, 20), and $\mathrm{d}$ is the degree of obstruction (minimum, 0; maximum, 2)

This index was compared to the historical Miller index used in pulmonary angiography [42]. Although both indexes have good reproducibility, vascular obstruction expressed by the Qanadli index is lower than that expressed by the Miller index. Cosmi et al. [43] studied both MDCT and planar Q scan in the same study, but none of the patients received both tests for radiation protection reasons. The prevalence of RPVO after 9 months of Vitamin $\mathrm{K}$ antagonist (VKA) therapy was close to $15 \%$ with the CTPA index but higher in patients screened with Q lung scan (nearly 28\% at 9 months). Ma et al. [41] followed 100 patients 12 months after pulmonary embolism with both CTPA and Q scan. They also reported a higher prevalence of RPVO with the Miller index (41.1\% abnormal V/Q scans) than the Qanadli CT index (15.9\% abnormal CT obstruction index). These data underlined a different RPVO detection sensitivity depending on the imaging technique. Unfortunately, RPVO has often been defined solely on the basis of perfusion scanning. The absence of associated ventilation scans may increase the risk of false positive RPVO, for example in patients with pulmonary parenchymal diseases such as chronic obstructive pulmonary disease (COPD) or interstitial pulmonary fibrosis. This gap may illustrate either a lack of specificity of lung scan or a lack of sensibility of MDCT.

Meysman et al. [44] compared dual-energy computed tomography (DECT) to V/Q SPECT to assess perfusion defects. In most of the patients (66.7\%), both of these imaging techniques yielded consistent results.

In summary, these data suggest good specificity of lung scan techniques, although further evaluations are needed. 


\section{I - 3 Epidemiology and evolution of RPVO}

The initial UPET [28] study assessed repermeabilization of vascular obstruction after PE with heparin therapy and monitored RPVO with planar scintigraphy. They observed a resolution of obstruction of $14.4 \%$ within the first 24 hours of anticoagulation therapy, $36.4 \%$ after five days, $52.2 \%$ after 14 days, $72.8 \%$ after 3 months of anticoagulation therapy and $75.8 \%$ after 1 year, reflecting some changes after 3 months of treatment.

It appears that the prevalence of RPVO varies depending on the imaging technique used, the duration of anticoagulation and the time between diagnosis and imaging assessment. Therapeutic advances have been made in PE care since the advent of VKA therapy. RPVO resolution decreased after 3 months of heparin therapy. This decrease seems to continue with VKA $[8,23,39,43,45-47]$. Unfortunately, the rate of RPVO has never been directly compared between heparins and VKAs.

Based on clinical studies conducted over the past two decades (Table 1), which define a persistent rate of RPVO> $10 \%$ with the Miller index, the following rates of RPVO under or after VKA therapy can be proposed as follows:

- $69 \%$ at 3 weeks [48];

- $46-66 \%$ at 3 months $[49,50]$;

- $25-52 \%$ at 6 months $[23,39,45,51]$;

- $28 \%$ at 9 months [43];

- $26 \%$ at 11 months [46];

- $25-29 \%$ at 1 year $[8,47]$.

Miniati et al. [52] prospectively followed 235 acute PE with a 1-year scintigraphic followup (planar Q scan with RPVO evaluation based on the Miller index). They showed that the extent 
of scintigraphic RPVO had progressively decreased over time. In this cohort, initial obstruction was greater than $43 \%$. At 1 month from diagnosis, $90 \%$ of the patients had residual vascular obstruction $<30 \%$. After 1 year, the rate of RPVO was $<15 \%$ in $90 \%$ of patients. Lung scan was considered normal in $65.1 \%$ of the patients.

The type of anticoagulation used may have an impact on RPVO. Direct Oral Anticoagulants (DOACs) have recently transformed PE treatment [53]. To our knowledge, there is only one study assessing RPVO for the anticoagulant drugs used, i.e. VKA and rivaroxaban. RPVO was evaluated with MDCT or planar Q lung scan after a 3-week course of anticoagulation in the first 400 patients included in the EINSTEIN-PE trial. The percentage of vascular obstruction was calculated using a semi-quantitative estimation of obstruction both with CT and Q lung scan and no difference in clot resolution was found between VKA and rivaroxaban. Nevertheless, this study confirms that planar lung scan was more sensitive to the detection of RPVO (normalization of perfusion in $31 \%$ of patients on planar lung scan versus $44 \%$ on CT scan). Unfortunately, this ancillary study was not designed to assess this endpoint, which limits the scope of these conclusions. Early RPVO assessment could also explain the high residual obstruction with both imaging techniques. 


\section{II - Clinical significance of residual defect}

\section{II- 1 RPVO and PE outcome}

The rate of RPVO after acute PE can be a useful tool for predicting early patient outcomes. In 2013, Meneveau et al. [54] evaluated the long-term prognostic value of RPVO. Their primary endpoint was a combination of criteria including death, recurrent PE and diagnosis of signs of heart failure after a 6-month follow-up. In their trial, RPVO was measured by a V/Q lung scan before discharge (average 6 days) in patients hospitalized for intermediate- or high-risk PE who survived to the acute phase. Their results showed that RPVO was associated with a significantly higher risk of unfavorable outcomes at 6 months (OR [CI95] 13.7 [4.7-39.8], $\mathrm{p}<0.0001$ ), with a sensitivity of $78.1 \%$ (67.6-88.6\%), specificity of $82.1 \%(71.5-92.7 \%)$, a positive predictive value of $24.5 \%$ (13.9-35.1\%), and a negative predictive value of $97.7 \%$ (94.5$100 \%)$. The authors recommend a systematic assessment of RPVO prior to discharge in patients with intermediate- or high-risk PE. An RPVO threshold $>35 \%$ could be used to distinguish between patients at high risk of adverse outcomes and patients likely to have a favorable longterm prognosis, with a high negative predictive value.

\section{II-2 RPVO and VTE recurrence}

The rate of RPVO evaluated with V/Q lung scan also appears to be a predictor of PE recurrence after a first episode. Pesavento [39] et al. assessed the impact of RPVO on the longterm outcome, with a combination of criteria including recurrent PE and CTEPH. Proven recurrent VTE was developed in $6.2 \%$ of the patients (CI95\% $4.5-8.3 \%$ ) and CTEPH in $1.7 \%$ (CI95\% 0.9-3.0\%). With these data, RPVO was identified to be an independent predictor of VTE recurrence and/or CTEPH (hazard ratio (CI95) 2.15 (1.07-4.33)). Although the proportion of VTE recurrence and CTEPH are lower than that reported in the literature [55], these data suggest 
that a single assessment of RPVO at 6 months could help risk-stratify patients with PE and guide therapeutic management.

Planquette et al.[56] also highlighted a link between RPVO and VTE recurrence in a monocentric cohort of 310 patients with symptomatic PE after a 3-month follow-up (excluding patients with extended anticoagulation treatment for CTEPH). They identified RPVO as an independent risk factor for VTE recurrence (HR(CI95) 1.94 (1.11-3.39).

In the REVERSE cohort, Wan et al. attempted to refine the link between RPVO and VTE recurrence [57]. In this cohort, 35 of the 307 (11.4\%) patients with initial unprovoked PE had an adjudicated episode of recurrent VTE during follow-up after discontinuation of anticoagulation. Subgroups based on the RPVO quartile show an increased incidence of VTE recurrence with RPVO extension. Compared to participants without RPVO, the HR (CI95) for recurrent VTE in patients with RPVO $0.1 \%-4.9 \%, 5.0 \%-9.9 \%,>10 \%$ were $2.0(0.5-7.3), 2.1(0.5-7.8)$ and 5.3 (1.8-15.4) respectively. Despite the sample-limited design of this study, it suggests that V/Q scan at the end of initial oral anticoagulation therapy may be useful to stratify the risk of recurrent VTE in patients with initial unprovoked PE.

Recently, Becattini et al [58] conducted a meta-analysis on the role of residual pulmonary obstruction on the risk of recurrent venous thromboembolism after acute pulmonary embolism. They confirmed an increased risk of recurrent VTE (11 studies; 2916 patients; OR 2.21; 95\% CI 1.63-3.01; I2 $=16 \%$ ) or PE (7 studies, 1801 patients, OR 2.98; 95\% CI 2.00-4.44; I2 = 11\%) if RPVO was observed on lung scan. The association between recurrent VTE and RPO is valid regardless of the methods used for RPO assessment on V/Q scan (i.e. visual or semi-quantitative evaluation) if the evaluation was made at least 3 months after acute PE. RPVO assessment on CTPA was not significantly associated with recurrent venous thromboembolism, probably due to significant heterogeneity. 
More recently this finding was also described in the PADIS-PE cohort [59] in which initial obstruction $>40 \%$ or persistent obstruction on V/Q lung scan $>5 \%$ at 6-month follow-up were independent predictors of recurrent VTE with HR (CI95) 2.90 (1.71-4.91) and 2.58 (1.564.29) respectively. PADIS-PE investigators proposed a score based on age, pulmonary obstruction measured either at diagnosis or at 6 months of anticoagulation and antiphospholipid antibodies. This score would identify patients at low risk of recurrent VTE in one fifth of cases and patients at a particular high risk in one third of cases, but it is still under validation.

\section{II-3 RPVO and functional evolution}

Acute obstruction of the pulmonary arteries has a direct impact on arterial oxygenation with a decrease in $\mathrm{PaO} 2$ [60]. This finding may have clinical implications. This phenomenon may be life-threating in the acute phase and expose patients to impaired long-term quality of life (QoL) [61]. This QoL alteration is mainly due to impaired physical performance and patientreported dyspnea [62]. Persistent dyspnea can be found in up to 50\% of patients with a history of PE [63]. Restoration of pulmonary perfusion following anticoagulation therapy has been associated with a direct improvement in $\mathrm{PaO} 2$ [52].

Sanchez et al. led a prospective observational cohort study to evaluate the clinical significance of RPVO [8]. At 12-month follow-up, patients with a perfusion defect on V/Q lung scan had a higher incidence of dyspnea and lower physical fitness with a reduced 6-min walking test (6MWT) distance. Systolic Pulmonary Arterial Pressure (PAP) had also increased compared to those without residual perfusion defects. In contrast, 100 patients of the ELOPE cohort [41] were followed after pulmonary embolism, with an imaging evaluation of perfusion. In this cohort, imaging findings (based both on Q lung scan and CTPA) after pulmonary embolism was not associated with exercise limitation. However, the ELOPE cohort has some limitation as 
the low number of patients, or the low level of RPVO at 12 month (mean obstruction of $5.6 \%$ at 12month on Q lung scan). RPVO is clearly not the unique cause able of dyspnea and functional limitation after PE, which are recognized as multidimensional [61]. More studies are needed to better understand role and implication of RPVO in this phenomenon.

The onset of such symptoms associated with RPVO but without pulmonary hypertension at rest is defined as chronic thromboembolic disease (CTED) [18]. The incidence of this phenomenon is largely unknown.

\section{II-4 Pathological syndrome after PE: CTEPH}

CTEPH is a major complication of acute PE associated with significant morbidity and mortality. The incidence of CTEPH is not well established, but different studies suggest that $1 \%$ to $3.8 \%$ of patients develop it within the 2 first years of follow-up [55,64]. Persistence of perfusion defects is necessary, but not sufficient to develop CTEPH. Distal pulmonary vascular remodeling plays a major role in PAP increase, although the mechanisms of remodeling and uncompleted repermeabilization are still unknown. Several mechanisms for poor thrombus clearance have been suggested: abnormal genetic variants of fibrinogen, predisposing pulmonary endothelial cell abnormalities, impairments of angiogenic processes and bacterial infection of fresh thrombi.

The diagnosis of CTEPH is based on 1) mean PAP $\geq 25 \mathrm{mmHg}$ with Pulmonary artery wedge pressure (PAWP) $\leq 15 \mathrm{mmHg}$ and 2) mismatched perfusion defects on lung scan and specific diagnostic signs for CTEPH on pulmonary angiography, CT or MR imaging. This finding may be obtained after at least 3 months of effective anticoagulation [6].

The current challenge is to predict patients at risk of developing CTEPH in order to implement early treatment. Several parameters, mainly linked with acute PE characteristics, have 
been associated with the risk of CTEPH onset [4]: delayed diagnosis, large pulmonary emboli, recurrent PE, idiopathic presentation, pulmonary hypertension at baseline [65], persistent RPVO and absence of normalized PAP or right ventricular function despite adequate anticoagulant treatment. Some of these risk factors are also proven risk factors for developing RPVO, proving the link between these two diseases. 


\section{III - Risk factors of residual perfusion defects after pulmonary embolism}

Since the pathophysiology is unknown, it is difficult to predict in which patient an RPVO will persist. Some predictors of RPVO have been identified in clinical trials and could justify specific monitoring to prevent clinical progression and thrombosis recurrence (Table 2). The risk factors identified could be linked to patient history or PE characteristics at baseline.

\section{III-1 Risk factors of RPVO linked with patient history}

In a prospective observational cohort study involving 254 patients, Sanchez et al. [8] evaluated the risk factors of RPVO. They reported that persistent RPVO increases with age at PE diagnosis (OR [CI95] for an increase of 10 years: 1.35 [1.11-1.63]). In a prospective multicentric cohort of 647 patients with acute PE after a 6-month anticoagulation period, Pesavento et al. [39] also consider older age as an independent risk factor of RPVO (OR [CI95] 1.03 [1.02-1.04]). Cosmi et al. [43] and Poli et al. [46] also have age as a predictor but failed to reach statistical significance due to a lack of statistical power. Older patients may have more comorbidities and less specific symptoms in the acute phase of PE, which could delay diagnosis and initiation of anticoagulant treatment [66], accumulating the risk of developing RPVO.

The integrity of the lung parenchyma probably has a role in adaptation and regeneration after PE. Cosmi et al. [43] reported that COPD at PE diagnosis is a substantial and independent predictor of RPVO (OR [CI95] 11.12 [2.44-50.76]). This association has methodological limitations. In this study, only a perfusion lung scan was performed to evaluate RPVO. However, COPD leads to increase in the number of matched V/Q anomalies. In this specified population, the lack of ventilation data could restrict the distinction between RPVO and COPD. 
In a monocentric prospective observational cohort of 47 patients, Meysman et al. [23] observed that persistence of perfusion defects was more frequent in females. This phenomenon has not been found in other cohorts and should be considered with caution.

Finally, previous VTE and RPVO appear to be associated independently (OR [CI95] 2.06 [1.03-4.11]) [8]. It is not clear that the vascular obstruction assessed during follow-up is related to long-term complications of previous VTE or acute PE. However, a similar proportion of patients with perfusion defects was observed in the group of patients without previous thromboembolic events compared to the overall population.

\section{III-2 Risk factors of RPVO linked with clinical presentation at PE diagnosis.}

Late diagnosis of PE leads to an increase in short term complications and the risk of PE extension [67]. It occurs mainly in older patients due to unspecific clinical presentation. Sanchez et al. found that an increase of 10 days from the first symptoms of VTE and diagnosis of PE is a risk factor of RPVO (OR [CI95] 1.17 [1.04-1.31]) [8]. This risk factor was also described by Lami et al. in a multivariate analysis [47] (OR [CI95] 11,07 [2,41-50,74]). In this cohort, the average time-to diagnosis was 15 days in the perfusion defect group versus 1 day in the control group $(\mathrm{p}=0,005)$.

In a population systematically evaluated with V/Q SPECT following PE, Alhadad et al. [25] clearly described the relationship between the initial extent of perfusion occlusion and defect resolution. A $10 \%$ increase in the extent of initial obstruction has also been associated with RPVO (OR [CI95] 1.34 [1.16-1.55]) [8]. This phenomenon has already been described by Planquette et al. [51] and Kaczyńska et al. [45]. They also reported that right ventricular dysfunction at diagnosis was an independent predictor of incomplete recanalization (OR [CI95] 7.03 [1.43-34.6]). Significant obstruction of the pulmonary arteries increases pulmonary 
resistance which may lead to heart failure. Pesavento et al. [39] found that a high clinical severity and extensive acute PE episode were associated with the persistence of pulmonary obstruction. They also described that an unprovoked PE episode was a risk factor of RPVO (OR [CI95] 1.40 [1.01-1.95]) in a multivariate analysis. 


\section{Conclusion}

RPVO after acute PE is a well-established complication, but with little known pathophysiology. The incidence is difficult to estimate because it is highly dependent on anticoagulant therapy, imaging techniques and the time required for evaluation. However, RPVO is linked with impaired physical performance and dyspnea (now known as CTED) and the cornerstone of CTEPH. More recently, it has been described to predict the risk of PE recurrence. The planar V/Q lung scan is currently the gold standard for the evaluation of RPVO and to rule out CTEPH. Some technical innovations such as V/Q SPECT or Dual Energy CT are promising tools but have yet to be validated against the gold standard.

Because of the major impact of post-PE syndrome, a call to action was recently launch to progress in comprehension and management of this syndrome [68]. For this reason, we propose the following recommendation and suggestions. Follow-up V/Q scan is mandatory in patients with persistent dyspnea and/or functional limitation after PE, in agreement with the ESC/ERS guidelines[10]. As RPVO scores (Figure 1, Figure 2) are now well validated and with a good reproducibility, we recommend to systematically quantified and notice RPVO quantified number in every report of V/Q scan. We suggest to realize a follow-up V/Q scan (ideally 6 months after the introduction of anticoagulation therapy) in patients in whom the length of therapy is not established, as in patients with an initial elevated obstruction index, based on the increased risk of PE recurrence in patients with RPVO. 


\section{Acknowledgements}

The draft has been by reviewed for English correction by "Laniel SA" 


\section{Bibliography}

[1] D. Jiménez, J. de Miguel-Díez, R. Guijarro, J. Trujillo-Santos, R. Otero, R. Barba, A. Muriel, G. Meyer, R.D. Yusen, M. Monreal, RIETE Investigators, Trends in the Management and Outcomes of Acute Pulmonary Embolism, J. Am. Coll. Cardiol. 67 (2016) 162-170. doi:10.1016/j.jacc.2015.10.060.

[2] S. Laporte, P. Mismetti, H. Décousus, F. Uresandi, R. Otero, J.L. Lobo, M. Monreal, J.I. Arcelus, R. Barba, A. Blanco, M. Barrón, J. Bugés, I. Casado, F. Conget, C. Falgá, C. Fernández-Capitán, L. Font, P. Gallego, F. García-Bragado, E. Grau, R. Guijarro, M. Guil, J. Gutiérrez, M.R. Gutiérrez, L. Hernández, D. Jiménez, R. Lecumberri, J.L. Lobo, F. López, L. López, López.I., O. Madridano, A. Maestre, J.J. Martín-Villasclaras, M. Monreal, J. Montes, M.D. Naufall, J.A. Nieto, M.J. Núñez, M.T. Orue, R. Otero, J.L. Pérez, J. Portillo, R. Rabuñal, E. Raguer, P. Román, N. Ruiz-Giménez, A.L. Samperiz, J.F. Sánchez, S. Soler, G. Tiberio, R. Tirado, J.A. Todolí, C. Tolosa, J. Trujillo, F. Uresandi, R. Valle, J. Vela, P. Mismetti, K. Rivron-Guillot, G. Le Gal, P. Di Micco, M.T. Iannuzo, R. Poggio, P. Prandoni, R. Quintavalla, E. Tiraferri, H. Decousus, F. Uresandi, R. Otero, J.L. Lobo, M. Monreal, RIETE Investigators, Clinical predictors for fatal pulmonary embolism in 15520 patients with venous thromboembolism: Findings from the Registro Informatizado de la Enfermedad TromboEmbolica venosa (RIETE) registry, Circulation. 117 (2008) 1711-1716. doi:10.1161/CIRCULATIONAHA.107.726232.

[3] G. Agnelli, H.R. Buller, A. Cohen, M. Curto, A.S. Gallus, M. Johnson, U. Masiukiewicz, R. Pak, J. Thompson, G.E. Raskob, J.I. Weitz, Oral Apixaban for the Treatment of Acute Venous Thromboembolism, N. Engl. J. Med. 369 (2013) 799-808. doi:10.1056/NEJMoa1302507.

[4] F. a Klok, T. van der Hulle, P.L. den Exter, M. Lankeit, M. V Huisman, S. Konstantinides, 
The post-PE syndrome: a new concept for chronic complications of pulmonary embolism., Blood Rev. 28 (2014) 221-226. doi:10.1016/j.blre.2014.07.003.

[5] M. Tavoly, H.S. Wik, P. Sirnes, L. Jelsness-jørgensen, J.P. Ghanima, F.A. Klok, P. Sandset, W. Ghanima, The impact of post-pulmonary embolism syndrome and its possible determinants, Thromb. Res. 171 (2018) 84-91. doi:10.1016/j.thromres.2018.09.048.

[6] N. Galiè, M. Humbert, J.-L. Vachiery, S. Gibbs, I. Lang, A. Torbicki, G. Simonneau, A. Peacock, A. Vonk Noordegraaf, M. Beghetti, A. Ghofrani, M.A. Gomez Sanchez, G. Hansmann, W. Klepetko, P. Lancellotti, M. Matucci, T. McDonagh, L.A. Pierard, P.T. Trindade, M. Zompatori, M. Hoeper, 2015 ESC/ERS Guidelines for the diagnosis and treatment of pulmonary hypertension, Eur. Heart J. 37 (2016) 67-119.

[7] S. V. Konstantinides, A. Torbicki, G. Agnelli, N. Danchin, D. Fitzmaurice, N. Gali??, J.S.R. Gibbs, M. V. Huisman, M. Humbert, N. Kucher, I. Lang, M. Lankeit, J. Lekakis, C. Maack, E. Mayer, N. Meneveau, A. Perrier, P. Pruszczyk, L.H. Rasmussen, T.H. Schindler, P. Svitil, A.V. Noordegraaf, J.L. Zamorano, M. Zompatori, S. Achenbach, H. Baumgartner, J.J. Bax, H. Bueno, V. Dean, C. Deaton, ??etin Erol, R. Fagard, R. Ferrari, D. Hasdai, A. Hoes, P. Kirchhof, J. Knuuti, P. Kolh, P. Lancellotti, A. Linhart, P. Nihoyannopoulos, M.F. Piepoli, P. Ponikowski, P.A. Sirnes, J.L. Tamargo, M. Tendera, W. Wijns, S. Windecker, D. Jimenez, W. Ageno, S. Agewall, R. Asteggiano, R. Bauersachs, C. Becattini, H. Bounameaux, H.R. B??ller, C.H. Davos, G.J. Geersing, M.A.G. Sanchez, J. Hendriks, M. Kilickap, V. Mareev, M. Monreal, J. Morais, B.A. Popescu, O. Sanchez, A.C. Spyropoulos, 2014 ESC Guidelines on the diagnosis and management of acute pulmonary embolism, Eur. Heart J. 35 (2014) 3033-3080. doi:10.1093/eurheartj/ehu283.

[8] O. Sanchez, D. Helley, S. Couchon, A. Roux, A. Delaval, L. Trinquart, M.A. Collignon, 
A.M. Fischer, G. Meyer, Perfusion defects after pulmonary embolism: Risk factors and clinical significance, J. Thromb. Haemost. 8 (2010) 1248-1255. doi:10.1111/j.15387836.2010.03844.x.

[9] S. Mehta, M. Frcpc, D.H. Frcpc, S.P. Frcpc, Diagnostic evaluation and management of chronic thromboembolic pulmonary hypertension : A clinical practice guideline, Can Respir J. 17 (2010) 301-334.

[10] N. Galiè, M. Humbert, J.-L. Vachiery, S. Gibbs, I. Lang, A. Torbicki, G. Simonneau, A. Peacock, A. Vonk Noordegraaf, M. Beghetti, A. Ghofrani, M.A. Gomez Sanchez, G. Hansmann, W. Klepetko, P. Lancellotti, M. Matucci, T. McDonagh, L.A. Pierard, P.T. Trindade, M. Zompatori, M. Hoeper, 2015 ESC/ERS Guidelines for the diagnosis and treatment of pulmonary hypertension, Eur. Heart J. 37 (2016) 67-119. doi:10.1093/eurheartj/ehv317.

[11] V.F. Tapson, D. Platt, F. Xia, S.A. Teal, M. De la Orden, C.H. Divers, C.A. Satler, V.N. Joish, R.N. Channick, Monitoring for Pulmonary Hypertension Following Pulmonary Embolism: The INFORM Study, Am. J. Med. 129: (2016) 978-85. doi:10.1016/j.amjmed.2016.03.006.

[12] S. V. Konstantinides, A. Torbicki, G. Agnelli, N. Danchin, D. Fitzmaurice, N. Galiè, J.S.R. Gibbs, M. V. Huisman, M. Humbert, N. Kucher, I. Lang, M. Lankeit, J. Lekakis, C. Maack, E. Mayer, N. Meneveau, A. Perrier, P. Pruszczyk, L.H. Rasmussen, T.H. Schindler, P. Svitil, A.V. Noordegraaf, J.L. Zamorano, M. Zompatori, S. Achenbach, H. Baumgartner, J.J. Bax, H. Bueno, V. Dean, C. Deaton, C. Erol, R. Fagard, R. Ferrari, D. Hasdai, A. Hoes, P. Kirchhof, J. Knuuti, P. Kolh, P. Lancellotti, A. Linhart, P. Nihoyannopoulos, M.F. Piepoli, P. Ponikowski, P.A. Sirnes, J.L. Tamargo, M. Tendera, W. Wijns, S. Windecker, D. Jimenez, W. Ageno, S. Agewall, R. Asteggiano, R. 
Bauersachs, C. Becattini, H. Bounameaux, H.R. Büller, C.H. Davos, G.J. Geersing, M.A.G. Sanchez, J. Hendriks, M. Kilickap, V. Mareev, M. Monreal, J. Morais, B.A. Popescu, O. Sanchez, A.C. Spyropoulos, 2014 ESC Guidelines on the diagnosis and management of acute pulmonary embolism, Eur. Heart J. 35 (2014) 3033-3080. doi:10.1093/eurheartj/ehu283.

[13] The PIOPED investigators, Value of the ventilation/perfusion scan in acute pulmonary embolism. Results of the prospective investigation of pulmonary embolism diagnosis (PIOPED)., JAMA. 263 (1990) 2753-2759. doi:10.1016/0736-4679(91)90350-O.

[14] A. Gottschalk, J.E. Juni, H.D. Sostman, R.E. Coleman, J. Thnall, K.A. Mckusick, J.W. Froeich, A. Alavi, Ventilation-perfusion scintigraphy in the PIOPED study . Part I . Data collection and tabulation Ventilation-Perfusion Scintigraphy in the PIOPED Study . Part I . Data Collection and Tabulation, J. Nucl. Med. 34 (1993) 1109-1118.

[15] A. Gottschalk, H.D. Sostman, R.E. Coleman, J.E. Juni, J. Thrall, K.A. McKusick, J.F. W., A. Alavi, G. Alexander, H.Dirk Sostman, R. Edward Coleman, Jack E. Juni, James Thrall, Kenneth A. McKusick, Jerry W.Froelich, Abass Alavi, A. Gottschalk, H.D. Sostman, R.E. Coleman, J.E. Juni, J. Thrall, K.A. McKusick, J.F. W., A. Alavi, Ventilation-Perfusion Scintigraphy in the PIOPED Study . Part II . Evaluation of the Scintigraphic Criteria and Interpretations, J Nucl Med. 34 (1993) 1119-1126.

http://jnm.snmjournals.org/content/34/7/1119.full.pdf (accessed May 30, 2017).

[16] P.B. Bonnefoy, N. Prevot, L. Bertoletti, A. Sanchez, J. Lima, L. Font, A. Gil Díaz, P. Llamas, J. Aibar, M. Monreal, Utilisation de la scintigraphie de ventilation/perfusion chez les patients diagnostiqués avec une embolie pulmonaire - Données du registre RIETE, Médecine Nucléaire. 43 (2019) 174-175. doi:10.1016/j.mednuc.2019.01.007.

[17] N. Tunariu, S.J.R. Gibbs, Z. Win, W. Gin-sing, A. Graham, P. Gishen, Ventilation - 
Perfusion Scintigraphy Is More Sensitive than Multidetector CTPA in Detecting Chronic Thromboembolic Pulmonary Disease as a Treatable Cause of Pulmonary Hypertension, $\mathrm{J}$ Nucl Med. 48 (2007) 680-685. doi:10.2967/jnumed.106.039438.

[18] N.H. Kim, M. Delcroix, X. Jais, M.M. Madani, H. Matsubara, E. Mayer, T. Ogo, V.F. Tapson, Chronic thromboembolic pulmonary hypertension, Eur Respir J. 53 (2018). doi:10.1183/13993003.01915-2018.

[19] M. Bajc, J.B. Neilly, M. Miniati, C. Schuemichen, M. Meignan, B. Jonson, EANM guidelines for ventilation/perfusion scintigraphy : Part 1. Pulmonary imaging with ventilation/perfusion single photon emission tomography, Eur. J. Nucl. Med. Mol. Imaging. 36 (2009) 1356-1370. doi:10.1007/s00259-009-1170-5.

[20] P.B. Bonnefoy, V. Margelidon-Cozzolino, M. Glenat, Contribution of CT acquisition coupled with lung scan in exploration of pulmonary embolism, Med. Nucl. 42 (2018) 248261. doi:10.1016/j.mednuc.2018.06.003.

[21] S. Hess, E. Frary, O. Gerke, P. Madsen, State-of-the-Art Imaging in Pulmonary Embolism: Ventilation/Perfusion Single-Photon Emission Computed Tomography versus Computed Tomography Angiography — Controversies, Results, and Recommendations from a Systematic Review, Semin. Thromb. Hemost. 42 (2016) 833-845. doi:10.1055/s-00361593376.

[22] J.J.J. Phillips, J. Straiton, R.T.T. Staff, Planar and SPECT ventilation/perfusion imaging and computed tomography for the diagnosis of pulmonary embolism: A systematic review and meta-analysis of the literature, and cost and dose comparison, Eur. J. Radiol. 84 (2015) 1392-1400. doi:10.1016/j.ejrad.2015.03.013.

[23] M. Meysman, H. Everaert, W. Vincken, Factors determining altered perfusion after acute pulmonary embolism assessed by quantified single-photon emission computed 
tomography-perfusion scan, Ann. Thorac. Med. 12 (2017) 30. doi:10.4103/18171737.197772.

[24] A. Begic, E. Opankovi, Č. Vesna, M. Rustempa, A. Ba, M. Miniati, J. Jögi, M. Bajc, Impact of ventilation / perfusion single-photon emission computed tomography on treatment duration of pulmonary embolism, Nucl. Med. Commun. 36 (2015) 162-167. doi:10.1097/MNM.0000000000000224.

[25] A. Alhadad, M. Miniati, H. Alhadad, A. Gottsäter, M. Bajc, The value of tomographic ventilation / perfusion scintigraphy ( V / PSPECT ) for follow-up and prediction of recurrence in pulmonary embolism, Thromb. Res. 130 (2012) 877-881. doi:10.1016/j.thromres.2012.09.002.

[26] Y. Maruoka, M. Nagao, S. Baba, T. Isoda, Y. Kitamura, Y. Yamazaki, K.K. Abe, M. Sasaki, K.K. Abe, H. Honda, Three-dimensional fractal analysis of 99mTc-MAA SPECT images in chronic thromboembolic pulmonary hypertension for evaluation of response to balloon pulmonary angioplasty: association with pulmonary arterial pressure, Nucl. Med. Commun. (2017) 1. doi:10.1097/MNM.0000000000000673.

[27] G. Meyer, M.A. Collignon, F. Guinet, A.A. Jeffrey, L. Barritault, H. Sors, Comparison of perfusion lung scanning and angiography in the estimation of vascular obstruction in acute pulmonary embolism, Eur. J. Nucl. Med. 17 (1990) 315-319. doi:10.1007/BF01268022.

[28] U.P. embolism T.S. Group, Urokinase Pulmonary Embolism Trial Phase 1 Results A Cooperative Study, Jama. 214 (1970) 2163-2172. doi:10.1001/jama.1971.03180220083023.

[29] The urokinase pulmonary embolism trial. A national cooperative study., Circulation. 47 (1973) II1-108. http://www.ncbi.nlm.nih.gov/pubmed/4266893 (accessed September 27, 2017). 
[30] M. Nijkeuter, M.M.C. Hovens, B.L. Davidson, M. V Huisman, Resolution of thromboemboli in patients with acute pulmonary embolism: a systematic review., Chest. 129 (2006) 192-7. doi:10.1378/chest.129.1.192.

[31] A.B. Van Rossum, P.M.T. Pattynama, E.R.T.A. Ton, F.E.E. Treurniet, J.-W. Arndt, B. Van Eck, G.J. Kieft, Pulmonary embolism: Validation of spiral CT angiography in 149 patients, Radiology. 201 (1996) 467-470. doi:10.1148/radiology.201.2.8888242.

[32] A. Perrier, P.-M. Roy, O. Sanchez, G. Le Gal, G. Meyer, A.-L. Gourdier, A. Furber, M.-P. Revel, N. Howarth, A. Davido, H. Bounameaux, Multidetector-row computed tomography in suspected pulmonary embolism., N. Engl. J. Med. 352 (2005) 1760-8. doi:10.1056/NEJMoa042905.

[33] A. Torbicki, A. Perrier, S. Konstantinides, G. Agnelli, N. Galiè, P. Pruszczyk, F. Bengel, A.J.B. Brady, D. Ferreira, U. Janssens, W. Klepetko, E. Mayer, M. Remy-Jardin, J.P. Bassand, A. Vahanian, J. Camm, R. De Caterina, V. Dean, K. Dickstein, G. Filippatos, C. Funck-Brentano, I. Hellemans, S.D. Kristensen, K. McGregor, U. Sechtem, S. Silber, M. Tendera, P. Widimsky, J.L. Zamorano, F. Andreotti, M. Ascherman, G. Athanassopoulos, J. De Sutter, D. Fitzmaurice, T. Forster, M. Heras, G. Jondeau, K. Kjeldsen, J. Knuuti, I. Lang, M. Lenzen, J. Lopez-Sendon, P. Nihoyannopoulos, L. Perez Isla, U. Schwehr, L. Torraca, J.L. Vachiery, N. Gali??, P. Pruszczyk, F. Bengel, A.J.B. Brady, D. Ferreira, U. Janssens, W. Klepetko, E. Mayer, M. Remy-Jardin, J.P. Bassand, A. Vahanian, J. Camm, R. De Caterina, V. Dean, K. Dickstein, G. Filippatos, C. Funck-Brentano, I. Hellemans, S.D. Kristensen, K. McGregor, U. Sechtem, S. Silber, M. Tendera, P. Widimsky, J.L. Zamorano, F. Andreotti, M. Ascherman, G. Athanassopoulos, J. De Sutter, D. Fitzmaurice, T. Forster, M. Heras, G. Jondeau, K. Kjeldsen, J. Knuuti, I. Lang, M. Lenzen, J. LopezSendon, P. Nihoyannopoulos, L. Perez Isla, U. Schwehr, L. Torraca, J.L. Vachiery, 
Guidelines on the diagnosis and management of acute pulmonary embolism, Eur. Heart J. 29 (2008) 2276-2315. doi:10.1093/eurheartj/ehn310.

[34] K.H. Nishiyama, S.S. Saboo, Y. Tanabe, D. Jasinowodolinski, M.J. Landay, F.U. Kay, Chronic pulmonary embolism : diagnosis, Cardiovasc. Diagnosis Ther. 8 (2018) 253-271. doi:10.21037/cdt.2018.01.09.

[35] J. Isidoro, P. Gil, G. Costa, J. Pedroso De Lima, C. Alves, N.C. Ferreira, Radiation dose comparison between V/P-SPECT and CT-angiography in the diagnosis of pulmonary embolism, Phys. Medica. 41 (2017) 93-96. doi:10.1016/j.ejmp.2017.04.026.

[36] F.A. Mettler, W. Huda, T.T. Yoshizumi, M. Mahesh, Effective Doses in Radiology and Diagnostic Nuclear Medicine: A Catalog, Radiology. 248 (2008) 254-263. doi:10.1148/radiol.2481071451.

[37] P.D. Stein, L.M. Freeman, H. Dirk Sostman, L.R. Goodman, P.K. Woodard, D.P. Naidich, A. Gottschalk, D.L. Bailey, F. Matta, A.Y. Yaekoub, C.A. Hales, R.D. Hull, K. V. Leeper, V.F. Tapson, J.G. Weg, H.D. Sostman, L.R. Goodman, P.K. Woodard, D.P. Naidich, A. Gottschalk, D.L. Bailey, F. Matta, A.Y. Yaekoub, C.A. Hales, R.D. Hull, K. V. Leeper, V.F. Tapson, J.G. Weg, SPECT in Acute Pulmonary Embolism, J. Nucl. Med. 50 (2009) 1999-2007. doi:10.2967/jnumed.109.063958.

[38] S.D. Qanadli, M. El Hajjam, A. Vieillard-baron, T. Joseph, B. Mesurolle, V.L. Oliva, O. Barré, F. Bruckert, O. Dubourg, P. Lacombe, New CT Index to Quantify Arterial Obstruction in Pulmonary Embolism : Comparison with Angiographic Index and Echocardiography, AJR. (2001) 1415-1420.

[39] R. Pesavento, L. Filippi, A. Palla, A. Visonà, C. Bova, M. Marzolo, F. Porro, S. Villalta, M. Ciammaichella, E. Bucherini, G. Nante, S. Battistelli, M.L. Muiesan, G. Beltramello, D. Prisco, F. Casazza, W. Ageno, G. Palareti, R. Quintavalla, S. Monti, N. Mumoli, N. 
Zanatta, R. Cappelli, M. Cattaneo, V. Moretti, F. Corà, M. Bazzan, A. Ghirarduzzi, A.C. Frigo, M. Miniati, P. Prandoni, SCOPE Investigators, Impact of residual pulmonary obstruction on the long-term outcome of patients with pulmonary embolism., Eur. Respir. J. 49 (2017) 1601980. doi:10.1183/13993003.01980-2016.

[40] P.L. den Exter, J. van Es, L.J.M. Kroft, P.M.G. Erkens, R.A. Douma, I.C.M. Mos, G. Jonkers, M.M.C. Hovens, M.F. Durian, H. ten Cate, L.F.M. Beenen, P.W. Kamphuisen, M. V. Huisman, Thromboembolic resolution assessed by CT pulmonary angiography after treatment for acute pulmonary embolism, Thromb. Haemost. 114 (2015) 1-9. doi:10.1160/TH14-10-0842.

[41] K.A. Ma, S.R. Kahn, A. Akaberi, C. Dennie, C. Rush, J.T. Granton, D. Anderson, P.S. Wells, M.A. Rodger, S. Solymoss, M.J. Kovacs, L. Rudski, A. Shimony, P. Hernandez, S.D. Aaron, E. Pena, G. Abikhzer, A.M. Hirsch, Serial imaging after pulmonary embolism and correlation with functional limitation at 12 months : Results of the ELOPE Study, Res Pr. Thromb Haemost. (2018) 1-8. doi:10.1002/rth2.12123.

[42] G.A.H. Miller, G.C. Sutton, I.H. Kerr, R. V Gibson, M. Honey, Comparison of Streptokinase and Heparin in Treatment of Isolated Acute Massive Pulmonary Embolism, Br. Med. J. 2 (1971) 681-684.

[43] B. Cosmi, M. Nijkeuter, M. Valentino, M. V. Huisman, L. Barozzi, G. Palareti, Residual emboli on lung perfusion scan or multidetector computed tomography after a first episode of acute pulmonary embolism, Intern. Emerg. Med. 6 (2011) 521-528. doi:10.1007/s11739-011-0577-8.

[44] M. Meysman, H. Everaert, N. Buls, K. Nieboer, J. De Mey, Comparison of ventilationperfusion single-photon emission computed tomography (V/Q SPECT) versus dual-energy CT perfusion and angiography (DECT) after 6 months of pulmonary embolism (PE) 
treatment, Eur. J. Radiol. 84 (2015) 1816-1819. doi:10.1016/j.ejrad.2015.05.023.

[45] A. Kaczyńska, M. Kostrubiec, R. Pacho, J. Kunikowska, P. Pruszczyk, Elevated D-dimer concentration identifies patients with incomplete recanalization of pulmonary artery thromboemboli despite 6 months anticoagulation after the first episode of acute pulmonary embolism, Thromb. Res. 122 (2008) 21-25. doi:10.1016/j.thromres.2007.08.020.

[46] D. Poli, C. Cenci, E. Antonucci, E. Grifoni, C. Arcangeli, D. Prisco, R. Abbate, M. Miniati, Risk of recurrence in patients with pulmonary embolism: predictive role of Ddimer and of residual perfusion defects on lung scintigraphy., Thromb. Haemost. 109 (2013) 181-6. doi:10.1160/TH12-07-0534.

[47] D. Lami, A.P. aola Cellai, E. Antonucci, C. Fiorillo, M. Becatti, E. Grifoni, C. Cenci, R. Marcucci, L. Mannini, M. Miniati, R. Abbate, D. Prisco, Residual perfusion defects in patients with pulmonary embolism are related to impaired fibrinolytic capacity, Thromb. Res. 134 (2014) 737-741. doi:10.1016/j.thromres.2014.07.013.

[48] J. Van Es, R.A. Douma, P.W. Kamphuisen, V.E.A. Gerdes, P. Verhamme, P.S. Wells, H. Bounameaux, A.W.A. Lensing, H.R. Büller, Clot resolution after 3 weeks of anticoagulant treatment for pulmonary embolism: Comparison of computed tomography and perfusion scintigraphy, J. Thromb. Haemost. 11 (2013) 679-685. doi:10.1111/jth.12150.

[49] R. Chopard, B. Genet, F. Ecarnot, M. Chatot, G. Napporn, A. Hyvert, K. Didier-Petit, F. Schiele, N. Meneveau, Detection of Residual Pulmonary Vascular Obstruction by Ventilation-Perfusion Lung Scan Late After a First Pulmonary Embolism, Am. J. Cardiol. 119 (2017) 1883-1889. doi:10.1016/j.amjcard.2017.03.002.

[50] M. Wartski, M. Collignon, T. Study, Incomplete Recovery of Lung Perfusion After 3 months in Patients with Acute Pulmonary Embolism Treated with Antithrombotic Agents, J Nucl Med. 41 (2000) 1043-1048. 
[51] B. Planquette, O. Sanchez, J.J. Marsh, P.G. Chiles, J. Emmerich, G. Le, G. Meyer, T. Wolfson, A.C. Gamst, R.E. Moore, G.B. Gugiu, A. Timothy, Fibrinogen and the Prediction of Residual Obstruction Manifested after Pulmonary Embolism Treatment, Eur. Respir. J. 52 (2018). doi:10.1183/13993003.01467-2018.

[52] M. Miniati, S. Monti, M. Bottai, E. Scoscia, C. Bauleo, L. Tonelli, A. Dainelli, C. Giuntini, Survival and Restoration of Pulmonary Perfusion in a Long-Term Follow-Up of Patients After Acute Pulmonary Embolism, Medicine (Baltimore). 85 (2006) 253-262. doi:10.1097/01.md.0000236952.87590.c8.

[53] L. Bertoletti, E. Ollier, C. Duvillard, X. Delavenne, M.-N. Beyens, E. De Magalhaes, F. Bellet, T. Basset, P. Mismetti, S. Laporte, Direct oral anticoagulants: Current indications and unmet needs in the treatment of venous thromboembolism, Pharmacol. Res. 118 (2017) 33-42. doi:10.1016/j.phrs.2016.06.023.

[54] N. Meneveau, O. Ider, M.F. Seronde, R. Chopard, S. Davani, Y. Bernard, F. Schiele, Long-term prognostic value of residual pulmonary vascular obstruction at discharge in patients with intermediate-to high-risk pulmonary embolism, Eur. Heart J. 34 (2013) 693701. doi:10.1093/eurheartj/ehs365.

[55] V. Pengo, A.W.A. Lensing, M.H. Prins, A. Marchiori, B.L. Davidson, F. Tiozzo, P. Albanese, A. Biasiolo, C. Pegoraro, S. Iliceto, P. Prandoni, Incidence of Chronic Thromboembolic Pulmonary Hypertension after Pulmonary Embolism, N. Engl. J. Med. 350 (2004) 2257-2264. doi:10.1056/NEJMoa032274.

[56] B. Planquette, A. Ferré, J. Peron, A. Vial-Dupuy, J. Pastre, G. Mourin, J. Emmerich, M.-A. Collignon, G. Meyer, O. Sanchez, Residual pulmonary vascular obstruction and recurrence after acute pulmonary embolism. A single center cohort study., Thromb. Res. 148 (2016) 70-75. doi:10.1016/j.thromres.2016.10.030. 
[57] T. Wan, M. Rodger, W. Zeng, P. Robin, M. Righini, M.J. Kovacs, M. Tan, M. Carrier, S.R. Kahn, P.S. Wells, D.R. Anderson, I. Chagnon, S. Solymoss, M. Crowther, R.H. White, L. Vickars, S. Bazarjani, G. Le Gal, Residual pulmonary embolism as a predictor for recurrence after a first unprovoked episode: Results from the REVERSE cohort study, Thromb. Res. (2017) 1-6. doi:10.1016/j.thromres.2017.11.020.

[58] C. Becattini, M. Giustozzi, P. Cerdà, L.A. Cimini, A. Riera, M. Giancarlo, Risk of recurrent venous thromboembolism after acute pulmonary embolism : Role of residual pulmonary obstruction and persistent right ventricular dysfunction . A meta - analysis, $\mathbf{J}$ Thromb Haemost. (2019). doi:10.1111/jth.14477.

[59] C. Tromeur, O. Sanchez, E. Presles, G. Pernod, L. Bertoletti, P. Jego, E. Duhamel, K. Provost, F. Parent, P. Robin, L. Deloire, F. Leven, F. Mingant, L. Bressollette, P.Y. Le Roux, P.Y. Salaun, M. Nonent, B. Pan-Petesch, B. Planquette, P. Girard, K. Lacut, S. Melac, P. Mismetti, S. Laporte, G. Meyer, D. Mottier, C. Leroyer, F. Couturaud, Risk factors for recurrent venous thromboembolism after unprovoked pulmonary embolism: the PADIS-PE randomised trial, Eur. Respir. J. 51 (2018). doi:10.1183/13993003.01202-2017.

[60] R. Prediletto, P. Paoletti, E. Fornai, A. Perissinotto, S. Petruzzelli, B. Formichi, S. Ruschi, A. Palla, A. Giannella-Neto, C. Giuntini, Natural course of treated pulmonary embolism. Evaluation by perfusion lung scintigraphy, gas exchange, and chest roentgenogram, Chest. 97 (1990) 554-561. doi:10.1378/chest.97.3.554.

[61] F. a. Klok, D.M. Cohn, S. Middeldorp, M. Scharloo, H.R. BüLler, K.W. van Kralingen, a. a. Kaptein, M. V. Huisman, Quality of life after pulmonary embolism: Validation of the PEmb-QoL Questionnaire, J. Thromb. Haemost. 8 (2010) 523-532. doi:10.1111/j.15387836.2009.03726.x.

[62] M. Tavoly, K.K. Utne, H.S. Wik, F.A. Klok, P.M. Sandset, W. Ghanima, Health-related 
quality of life after pulmonary embolism : a cross-sectional study, (2016). doi:10.1136/bmjopen-2016-013086.

[63] F. a. Klok, J.E. Tijmensen, M.L. a Haeck, K.W. van Kralingen, M. V. Huisman, Persistent dyspnea complaints at long-term follow-up after an episode of acute pulmonary embolism: Results of a questionnaire, Eur. J. Intern. Med. 19 (2008) 625-629. doi:10.1016/j.ejim.2008.02.006.

[64] C. Becattini, A. Giancarlo, R. Pesavento, M. Silingardi, R. Poggio, R. Taliani Maria, W. Ageno, Incidence of Chronic Thromboembolic Pulmonary Hypertension After a First Episode of Pulmonary Embolism *, Chest. 130 (2006) 172-175. doi:10.1378/chest.130.1.172.

[65] S. Yang, Y. Yang, Z. Zhai, T. Kuang, J. Gong, S. Zhang, J. Zhu, L. Liang, Y.H. Shen, C. Wang, Incidence and risk factors of chronic thromboembolic pulmonary hypertension in patients after acute pulmonary embolism, J. Thorac. Dis. 7 (2015) 1927-1938. doi:10.3978/j.issn.2072-1439.2015.11.43.

[66] G. Le Gal, M. Righini, P.-M. Roy, G. Meyer, D. Aujesky, A. Perrier, H. Bounameaux, Differential value of risk factors and clinical signs for diagnosing pulmonary embolism according to age., J. Thromb. Haemost. 3 (2005) 2457-64. doi:10.1111/j.15387836.2005.01598.x.

[67] J.A. Kline, J. Hernandez-Nino, A.E. Jones, G.A. Rose, H.J. Norton, C.A. Camargo, Prospective Study of the Clinical Features and Outcomes of Emergency Department Patients with Delayed Diagnosis of Pulmonary Embolism, Acad. Emerg. Med. 14 (2007) 592-598. doi:10.1197/j.aem.2007.03.1356.

[68] F.A. Klok, S. Barco, B. Siegerink, Measuring functional limitations after venous thromboembolism: A call to action, Thromb. Res. 178 (2019) 59-62. 
doi:10.1016/j.thromres.2019.04.003. 


\section{Figures}

Figure 1: Meyer criteria for estimation of RPVO on V/Q lung scan.

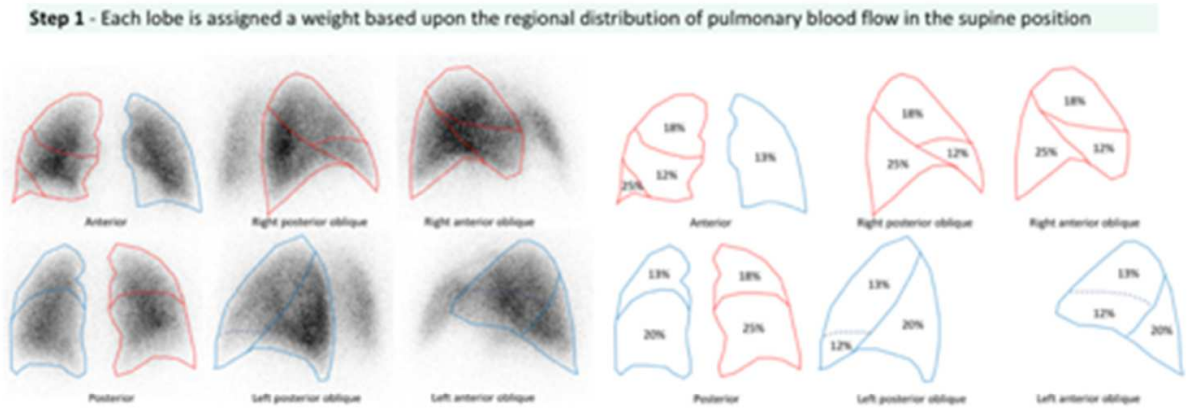

Step 2 - For each lobe, a semi-quantitative perfusion score $(0,0.25,0.5,0.75$ or 1$)$ is estimated from the film by comparison with the photodensity of an apparently normally perfused area;

Exemple - Semi-quontitotive perfusian score applind to obnormal perfusion in Right lower labe

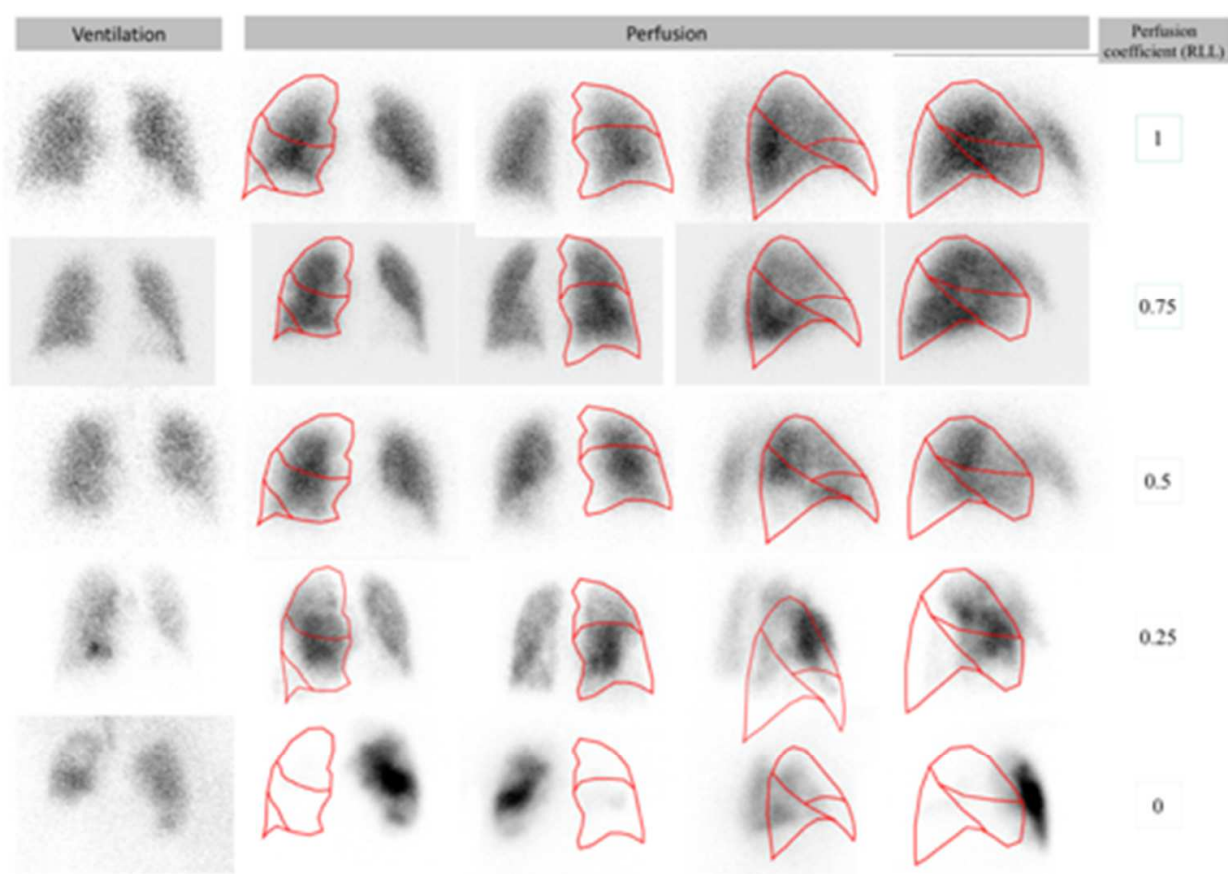

Step 3 - Each lobar perfusion score is then calculated by multiplying the weight by perfusion score

Step 4 - The overall perfusion score is determined by summing the six separate lobar perfusion scores and the percentage of vascular obstruction is then calculated as (1- overall perfusion score) $\times 100$. 
Figure 2: Qanadli criteria for estimation of RPVO on MDCT

Step 1 - The arterial tree of each lung is divided into 10 segmental arteries

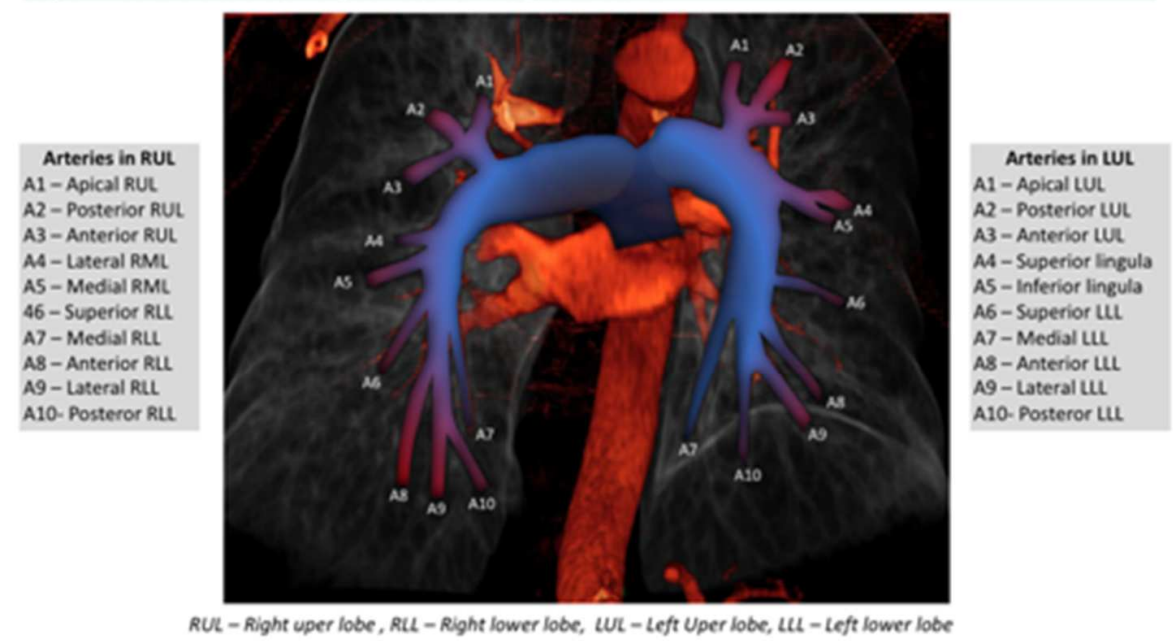

Step 2 - 1 point is attributed for the presence of an embolus in a segmental artery. Some emboli in the most proximal arterial level are scored a value equal to the number of segmental arteries arising distally.

Step 3 - To provide additional information about the residual perfusion distal to the embolus, a weighting factor is assigned to each value, depending on the degree of vascular obstruction. This factor is equal to zero when no thrombus is observed; 1 , when partially occlusive thrombus is observed; or 2 with total occlusion.

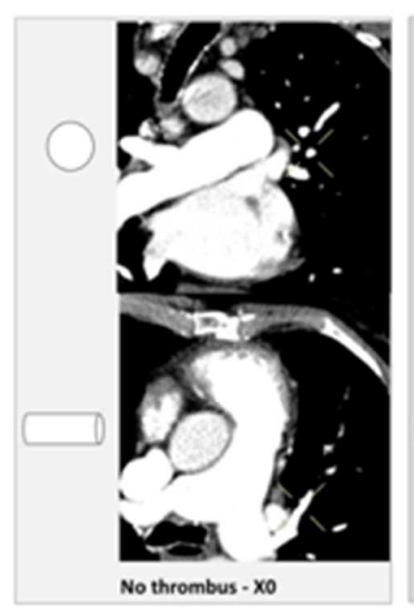

No thrombus - $x$
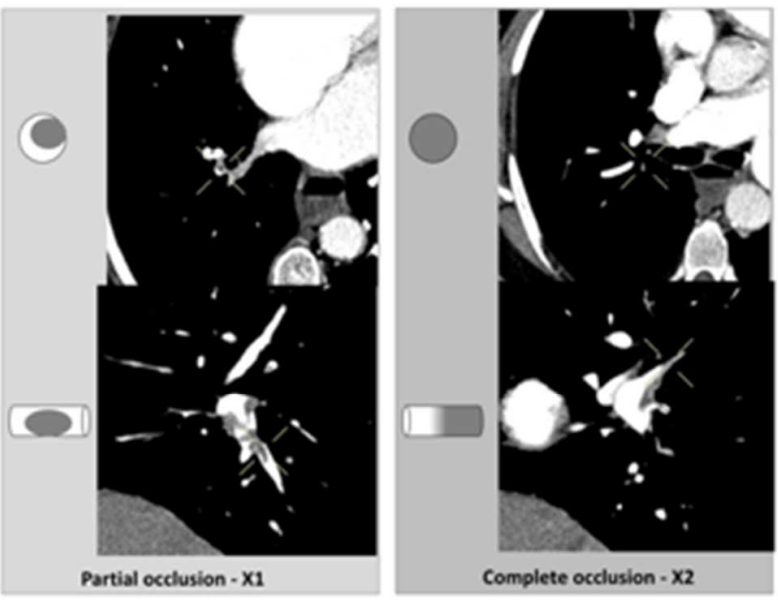

Step 4 - Patient score was obtained by summing the 20 arteries scores. The percentage of vascular obstruction is calculated by dividing the patient score by the maximal total score ( 40 par patient) and by multiplying the result by 100 . 


\section{Table}

Table 1: prevalence of RPVO according to previous studies

\begin{tabular}{|c|c|c|c|c|c|c|}
\hline Study & Year & Treatment & n patient & $\begin{array}{l}\text { Prevalence of } \\
\text { residual } \\
\text { anomalies }\end{array}$ & $\begin{array}{l}\text { Time for } \\
\text { assessment }\end{array}$ & Technique for assessment \\
\hline UPET [28] & 1970 & $\begin{array}{l}\text { Heparin } \\
\text { Urokinase }\end{array}$ & $\begin{array}{l}27 \\
30\end{array}$ & $\begin{array}{l}24.2 \% \\
26.7 \%\end{array}$ & $\begin{array}{l}1 y \\
1 y\end{array}$ & $\begin{array}{l}\text { Planar } V / Q \text { lung scan } \\
\text { Planar } V / Q \text { lung scan }\end{array}$ \\
\hline UPET [29] & 1973 & & 105 & $16 \%$ & $1 y$ & Planar V/Q lung scan \\
\hline Wartski et al. [50] & 2000 & $V K A$ & 157 & $66 \%$ & $3 m o$ & $\begin{array}{l}\text { Planar } Q \text { lung scan } \\
\text { (Meyer index) }\end{array}$ \\
\hline Miniati et al. [52] & 2006 & $V K A$ & 235 & $34.9 \%$ & $1 y$ & $\begin{array}{l}\text { Planar } Q \text { lung scan } \\
\text { (Meyer index) }\end{array}$ \\
\hline Kaczyńska et al. [45] & 2008 & $V K A$ & 55 & $70 \%$ & $6 m o$ & Planar $Q$ lung scan \\
\hline Sanchez et al. [8] & 2010 & $V K A$ & 254 & $29 \%$ & $1 y$ & $\begin{array}{l}\text { Planar V/Q lung scan } \\
\text { (Meyer index) }\end{array}$ \\
\hline Cosmi et al. [43] & 2011 & $V K A$ & $\begin{array}{l}80 \\
93\end{array}$ & $\begin{array}{l}15 \% \\
28 \%\end{array}$ & $\begin{array}{l}9 m o \\
9 m o\end{array}$ & $\begin{array}{l}\text { MDCT(5 scale index }) \\
\text { Planar } Q \text { lung scan }\end{array}$ \\
\hline Alhadad et al. [25] & 2012 & $V K A$ & 227 & $49 \%$ & $6 m o$ & $\begin{array}{l}\text { V/Q SPECT (36 points } \\
\text { score })\end{array}$ \\
\hline Van es et al. [48] & 2013 & $\begin{array}{l}\text { VKA/ } \\
\text { rivaroxaban }\end{array}$ & $\begin{array}{l}129 / 135 \\
38 / 45 \\
\end{array}$ & $\begin{array}{l}56 \% \\
69 \% \\
\end{array}$ & $3 s$ & $\begin{array}{l}M D C T \\
\text { Planar V/Q (Meyer index) }\end{array}$ \\
\hline Poli et al. [46] & 2013 & $V K A$ & 235 & $26 \%$ & $11 \mathrm{mo}$ & Planar $Q$ \\
\hline Lami et al. [47] & 2014 & $V K A$ & 71 & $25 \%$ & $1 y$ & $\begin{array}{l}\text { Planar V/Q lung scan } \\
\text { (Meyer index) }\end{array}$ \\
\hline Den Exter et al. [40] & 2015 & $V K A$ & 157 & $15.9 \%$ & $9 m o$ & MDCT (Qanadli index) \\
\hline Begic et al. [24] & 2015 & $V K A$ & 67 & $\begin{array}{l}35 \% \\
17 \% \\
\end{array}$ & $\begin{array}{l}3 m o \\
6 m o \\
\end{array}$ & $\begin{array}{l}\text { V/Q SPECT (36 points } \\
\text { score })\end{array}$ \\
\hline $\begin{array}{l}\text { Planquette et al. } \\
{[56]}\end{array}$ & 2016 & $V K A$ & 321 & $19 \%$ & $9 m o$ & $\begin{array}{l}\text { Planar V/Q lung scan } \\
\text { (Meyer index) }\end{array}$ \\
\hline Meysman et al. [23] & 2017 & $V K A$ & 46 & $52.2 \%$ & $6 m o$ & Q-SPECT lung scan) \\
\hline Chopard et al. [49] & 2017 & $V K A$ & 241 & $29 \%$ & $3 m o$ & $\begin{array}{l}\text { Planar V/Q lung scan } \\
\text { (Meyer index) }\end{array}$ \\
\hline Wan et al. [57] & 2017 & $V K A$ & 289 & $60 \%$ & $5-7 m o$ & $\begin{array}{l}\text { Planar V/Q lung scan } \\
\text { (Meyer index) }\end{array}$ \\
\hline Pesavento et al. [39] & 2017 & $V K A$ & 647 & $50.1 \%$ & $6 m o$ & $\begin{array}{l}\text { Planar Q lung scan } \\
\text { (Meyer index) }\end{array}$ \\
\hline Ma et al. [41] & 2018 & $V K A$ & 100 & $\begin{array}{l}15.9 \% \\
46.4 \% \\
41.1 \% \\
\end{array}$ & $\begin{array}{l}12 \mathrm{mo} \\
6 \mathrm{mo} \\
12 \mathrm{mo} \\
\end{array}$ & $\begin{array}{l}\text { MDCT (Qanadli index) } \\
\text { Planar } Q \text { lung scan } \\
\text { (Meyer index) }\end{array}$ \\
\hline Planquette et al. [51] & 2018 & $N A$ & $\begin{array}{l}102 \\
182 \\
\end{array}$ & $\begin{array}{l}28.4 \% \\
25.3 \% \\
\end{array}$ & $\begin{array}{l}6 m o \\
6 m o \\
\end{array}$ & $\begin{array}{l}\text { Planar V/Q lung scan } \\
\text { (Meyer index) }\end{array}$ \\
\hline
\end{tabular}


Table 2: risk factor to present residual occlusion after APE.

\begin{tabular}{|c|c|c|c|c|c|c|}
\hline Study & Year & $\begin{array}{l}\text { Treat } \\
\text { ment }\end{array}$ & n patient & Risk factor (univariate) & Risk factor (multivariate) & $\begin{array}{l}\text { OR[CI95] } \\
\text { m: multivariate } \\
\text { u: univariate }\end{array}$ \\
\hline $\begin{array}{l}\text { Kaczyńska } \\
\text { et al. [45] }\end{array}$ & 2008 & $V K A$ & 55 & $\begin{array}{l}\text { - D-Dimer concentration at } 6 \\
\text { months }>350 \quad \text { ventricular } \\
\text { Right dysfunction at diagnosis } \\
\quad\end{array}$ & $\begin{array}{ll}- & \text { D-Dimer concentration at 6month }>350 \\
- & \text { Right ventricular dysfunction at diagnosis }\end{array}$ & $\begin{array}{l}-18.58(1.97-175.19)^{m} \\
-7.03(1.43-34.6)^{m}\end{array}$ \\
\hline $\begin{array}{l}\text { Sanchez et } \\
\text { al. [8] }\end{array}$ & 2010 & $V K A$ & 254 & & 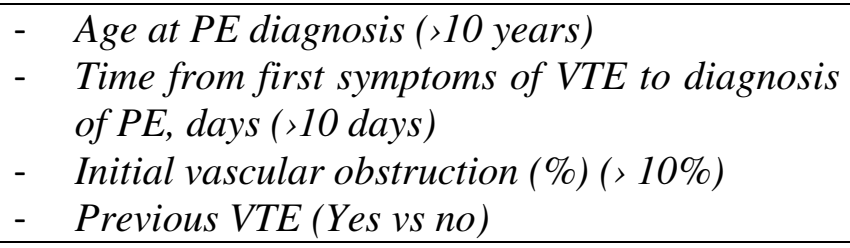 & $\begin{array}{ll}- & 1.35(1.11-1.63)^{m} \\
- & 1.17(1.04-1.31)^{m} \\
- & 1.34(1.16-1.55)^{m} \\
- & 2.06(1.03-4.11)^{m}\end{array}$ \\
\hline $\begin{array}{l}\text { Cosmi et } \\
\text { al. }[43]\end{array}$ & 2011 & $V K A$ & 93 & - $\quad$ Pulmonary disease & - Pulmonary disease & - $\quad 11.12(2.44-50.76)^{m}$ \\
\hline $\begin{array}{l}\text { Poli et al. } \\
{[46]}\end{array}$ & 2013 & $V K A$ & 235 & - Age & - & $-\quad N A$ \\
\hline $\begin{array}{l}\text { Lami et al. } \\
\text { [47] }\end{array}$ & 2014 & $V K A$ & 71 & - & $\begin{array}{ll}- & \text { Fibrin lysis time } \\
- & \text { Time to diagnostic }\end{array}$ & $\begin{array}{ll}- & 7.1(1.78-2.35)^{m} \\
- & 11.07(2.41-50.74)^{m}\end{array}$ \\
\hline $\begin{array}{l}\text { Meysman } \\
\text { et al. [23] }\end{array}$ & 2017 & $V K A$ & 47 & & - Gender & - $\quad N A$ \\
\hline $\begin{array}{l}\text { Pesavento } \\
\text { et al. [39] }\end{array}$ & 2017 & $V K A$ & 647 & $\begin{array}{l}\text { - } \text { Older age, } \\
\text { - } \quad \text { unprovoked } \\
\text { presentation, } \\
\text { - } \\
\text { higher clinical severity } \\
\text { - extensive acute pulmonary } \\
\text { embolism episode }\end{array}$ & $\begin{array}{l}\text { - Older age } \\
\text { - } \quad \text { Unprovoked pulmonary embolism } \\
\text { - } \quad------ \\
-\end{array}$ & $\begin{array}{ll}- & 1.03,(1.02-1.04)^{m} \\
- & 1.40,(1.01-1.95)^{\mathrm{m}} \\
- & ------ \\
- & -----\end{array}$ \\
\hline $\begin{array}{l}\text { Planquette } \\
\text { et al. [51] }\end{array}$ & 2018 & $N A$ & $\begin{array}{l}102 \\
(\text { cohort } 1) \\
182 \\
(\text { cohort } 2)\end{array}$ & & $\begin{array}{l}\text { - extent of pulmonary vascular obstruction at } \\
\text { the onset of PE } \\
\text { - fibrinogen B } \beta \text {-chain monosialylation }\end{array}$ & \\
\hline
\end{tabular}




\author{
Abbreviations \\ 6MWT: 6-min walk test \\ 99mTc: Technetium-99m \\ COPD: Chronic obstructive pulmonary disease \\ CPA: computed pulmonary angiography \\ CT: computed tomography \\ CTEPH: Chronic thromboembolic pulmonary hypertension \\ MDCT: Multi-detector computed tomography \\ DOAC: Direct oral anticoagulants \\ PAP: Pulmonary artery pressure \\ PAWP: Pulmonary artery wedge pressure \\ PE: Pulmonary embolism \\ QoL: Quality of life \\ RPVO: Residual pulmonary vascular obstruction \\ SDCT: Single-detector computed tomography \\ SPECT: Single photon emission computed tomography \\ V/Q: Ventilation/perfusion
}

